This item was submitted to Loughborough's Research Repository by the author.

Items in Figshare are protected by copyright, with all rights reserved, unless otherwise indicated.

\title{
Electrical conduction characteristics of solid metal anisotropic conductive adhesive particles
}

PLEASE CITE THE PUBLISHED VERSION

PUBLISHER

(c) IEEE

LICENCE

CC BY-NC-ND 4.0

REPOSITORY RECORD

Dou, Guangbin, David C. Whalley, and Changqing Liu. 2019. "Electrical Conduction Characteristics of Solid Metal Anisotropic Conductive Adhesive Particles". figshare. https://hdl.handle.net/2134/3977. 
This item was submitted to Loughborough's Institutional Repository (https://dspace.lboro.ac.uk/) by the author and is made available under the following Creative Commons Licence conditions.

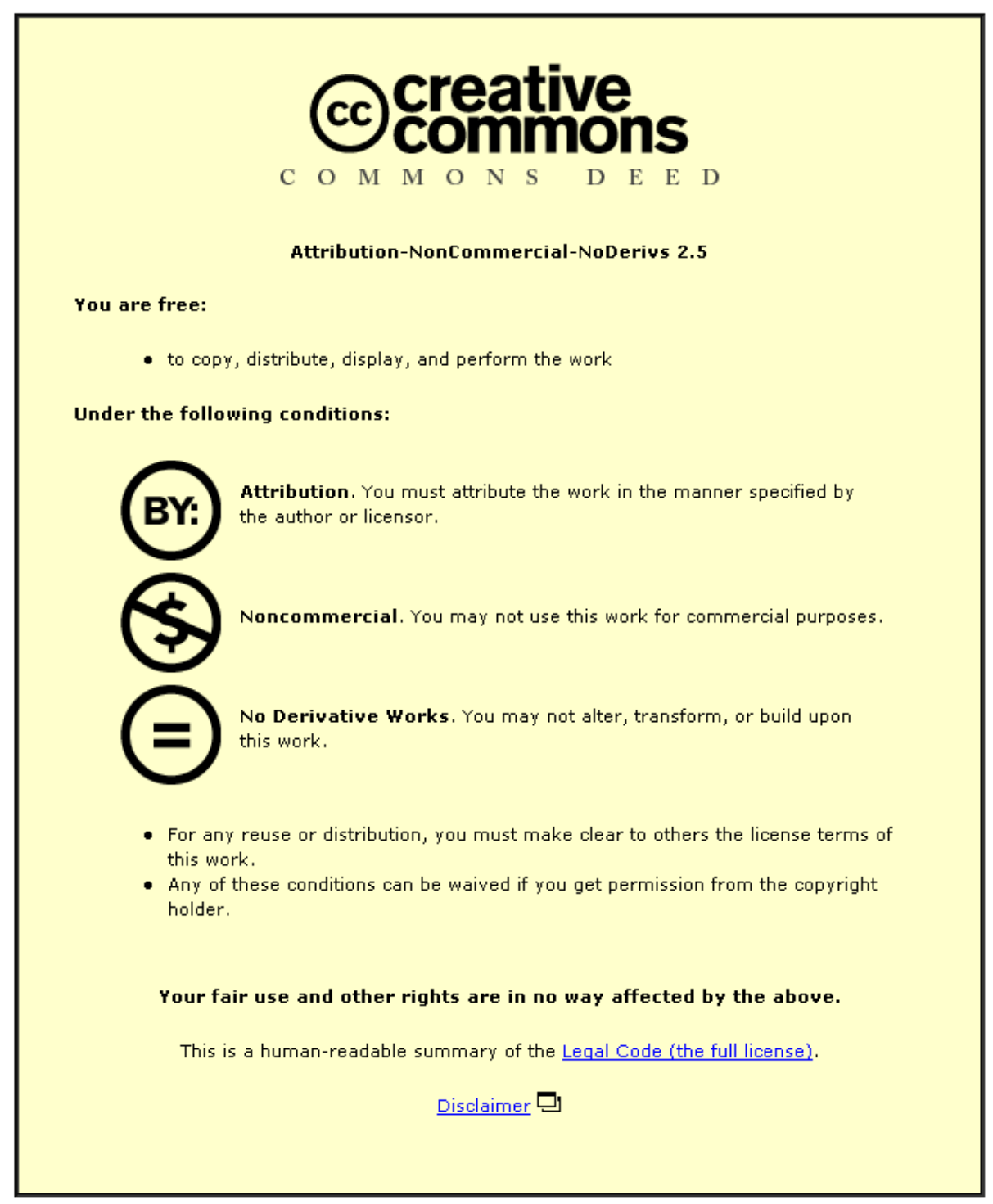

For the full text of this licence, please go to: http://creativecommons.org/licenses/by-nc-nd/2.5/ 
Polytronic 2004

\title{
Electrical Conduction Characteristics of Solid Metal Anisotropic Conductive Adhesive Particles
}

\author{
Guangbin Dou, David C. Whalley and Changqing Liu \\ Wolfson School of Mechanical and Manufacturing Engineering, Loughborough University, Leicestershire LE11 3TU, \\ United Kingdom. \\ Email: gb.dou@1boro.ac.uk
}

\begin{abstract}
Anisotropic Conductive Adhesives (ACAs) have been used in fine pitch electronics packaging for over a decade and provide a high density and low temperature bonding method in a range of niche applications. In an ACA assembly, individual particles act as electrical conductors, providing current paths for fine pitch electronics interconnections. This paper presents a model of the electrical conduction characteristics of the solid metal particles used in some ACAs. Conduction through such ACA particles results from contact between the component and substrate pads and the particle, which is deformed by the assembly process. In order to investigate the effect of the extent of particle deformation, or transformation degree, upon the particle resistance, the particle transformation factor is defined. A mathematical model of the electrical resistance of an ACA particle, which is an integral function of the transformation factor and the particle geometry, has been developed from a physical model of the ACA particle. MathCAD software has been used to provide solutions for this function. According to these numerical solutions, the greater the particle transformation, the lower the particle resistance will be. In conclusion, it is shown that the ACA particle resistance is determined by the particle transformation and the particle geometries. Finally, the resistance function will explain the conductive mechanism of a deformed metal ACA particle.
\end{abstract}

\section{Introduction}

ACAs are conceptually a simple method for the interconnection of high density electrodes on electronic components. They offer advantages in terms of low assembly temperature, high interconnect density, and compatibility with metalisations unsuitable for use with soldering processes $[1,2]$. ACAs are experiencing a significant growth in use, since they are well suited to a number of niche applications, such as in smart cards, in hybrid circuit and chip on board die-attach, and in LCD display assembly [2].

Electrical conduction through an ACA is achieved by the mechanical deformation of conductive particles under pressure and heat. In order to understand the electrical and mechanical behaviour of ACA materials, three key issues require to be considered. First, sufficient conducting particles must be trapped during the bonding process to guarantee electrical contact with both conductor surfaces. Second, the degree of deformation of the conducting particles during bonding determines the contact area and therefore the electrical characteristics of the interconnection. Third, the residual stress state after assembly significantly influences the mechanical and electrical performance under testing conditions and in service [3]. Addressing these issues is the main challenge in the application of ACA assembly. The third issue has been investigated in many studies e.g. [4,5] and there have been a few studies regarding the first topic e.g. $[6,7]$, however relatively few studies have addressed the second topic e.g. $[8,9]$. These studies have mainly focused on estimating the contact constriction resistances between the particles and conductors. Simplified models of the conductivity of ACA particles are presented in references $[9,10]$ and two models specifically for metal coated polymer particles are presented in $[11,12]$. This paper will focus on the electrical conduction aspects of solid metal conductor particles and will present a new electrical model of how these particles are affected by the transformation degree. Results are presented for the predicted resistance of solid silver $(\mathrm{Ag})$ ACA particles.

Electrical conduction through an ACA is somewhat complicated, with existing theoretical models not fully agreeing with experimental results. Many modelling studies have focused on this topic e.g. [13,14]. A single ACA connection between a chip and substrate includes three parts, the chip bump, the ACA particles and the substrate pad, as shown in Fig. 1 .

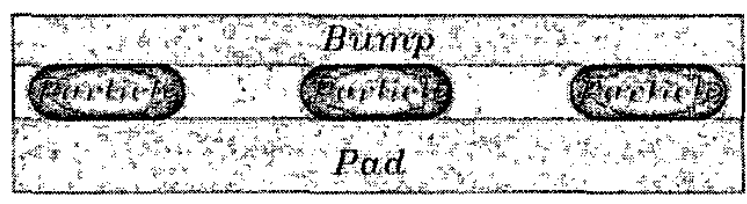

Figure 1. Cross section of an ACA connection

The $D C$ current path through the bump, a single particle and the pad can be divided into five parts, which can be represented as five independent resistors as shown in Fig. 2.

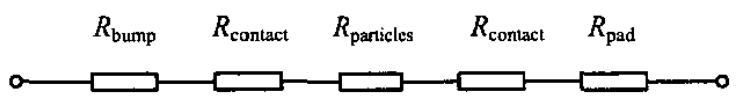

Figure 2. Equivalent circuit of an ACA joint

The bump and pad resistances are simply determined by their geometry and the resistivity of the metal they are made from, and can be readily calculated. The stationary contact 
resistances are caused by the mechanical connection between the conductor particle and the two conductor surfaces, a complex issue discussed further by Dou et al. [15]. The particle resistance is determined by the extent of deformation of the metal particle resulting from the bonding process. This deformation is the extent of compression of the particle, or transformation degree. In addition to the transformation degree, the resistivity and diameter of the metal particle will affect the particle resistance. The purpose of this paper is to present a model of the metal particle resistance as a function of the transformation degree and the particle geometry.

\section{The Transformation Degree of an ACA Particle}

Transformation of an ACA particle is caused by the bonding process under pressure and heat. The degree of the transformation, $k$, is defined as,

$$
k(\Delta d)=\frac{\Delta d}{d} \times 100 \% \text {. }
$$

Where the sphere diameter, $d$, is the distance between the chip bump and the substrate pad before deformation and $\Delta d$ is the transformation displacement after the particle is deformed as shown in Fig. 3 [8]

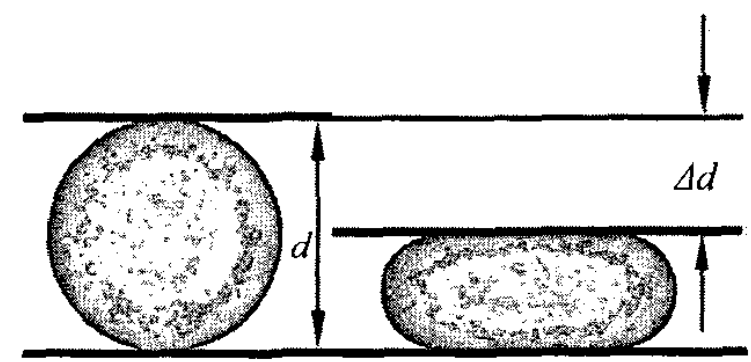

Figure 3. Transformation degree of an ACF particle

\section{Electrical Resistance Function of a Solid Metal ACA Particle}

During the transformation process, the particle volume is not changed, hence the original sphere volume $V_{\text {sphere }}$ is equal to the deformed volume $\mathrm{V}_{\text {deformed }}$,

$$
V_{\text {deformed }}=V_{\text {sphere }}=\frac{4}{3} \pi\left(\frac{d}{2}\right)^{3} \text {. }
$$

Fig. 4-a shows a deformed metal particle, whose crosssectional profile in the $y z$-plane is illustrated in Fig. 4-b. As the illustration shows, the cross-section profile consists of a rectangular area and two approximately semi circular areas. The outline of the right hand semi-circular area is described by the equation,

$$
[y-R]^{2}+z^{2}=\left(\frac{h}{2}\right)^{2}
$$

where $R$ is the radius of the upper circular area where contact is made, and $h$ is the height of the deformed particle (Fig. 4-b). Both $\mathrm{R}$ and $h$ are functions of $k$ and $d . h$ is defined as,

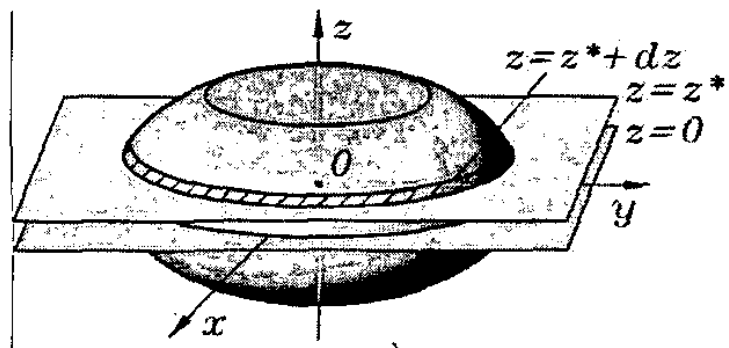

a)

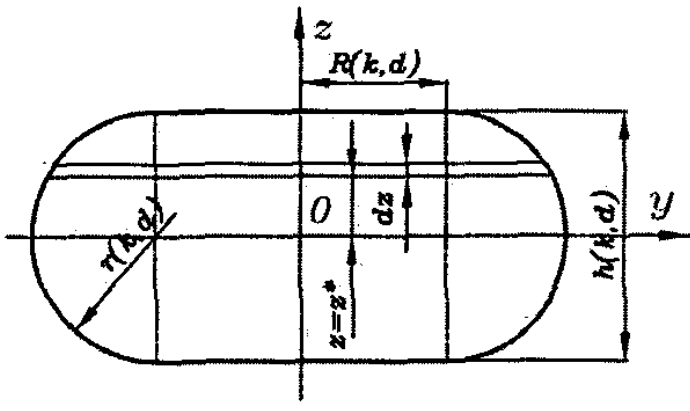

b)

Figure 4. Geometry of a deformed ACA particle

$h(k, d)=(1-k) d$.

The cross-sectional profile of the deformed particle in the plane $z=z^{*}$ is a circular area, with a radius of $y^{*}$, and therefore has an area of $\pi\left(y^{*}\right)^{2}$. Substituting $z=z^{*}$ into Equation (3) and simplifying, we obtain $\left(y^{*}\right)^{2}$,

$$
\left(y^{*}\right)^{2}=\left[\sqrt{\left(\frac{h}{2}\right)^{2}-\left(z^{*}\right)^{2}}+R\right]^{2} .
$$

Thus, the area of the circle is,

$$
S^{*}=\pi\left[\sqrt{\left(\frac{h}{2}\right)^{2}-\left(z^{*}\right)^{2}}+R\right]^{2} \text {. }
$$

As Fig. 4 shows, the volume of the particle between $z=z^{*}$ and $z=z^{*}+d z$ is $V^{*}=S^{*} d z$, Substituting Equation (6) into $V^{*}=S^{*} d z$, gives,

$$
V^{*}=S^{*} d z=\pi\left[\sqrt{\left(\frac{h}{2}\right)^{2}-\left(z^{*}\right)^{2}}+R\right]^{2} d z
$$

Consequently, the deformed particle volume can be obtained by integrating equation (7) from $-h / 2$ to $+h / 2$ along the $z$ axis,

$$
V_{\text {deformed }}=\pi \int_{-h / 2}^{h / 2} V^{*}=\pi \int_{-h / 2}^{h / 2}\left[\sqrt{\left(\frac{h}{2}\right)^{2}-\left(z^{*}\right)^{2}}+R\right]^{2} d z \text {. (8) }
$$

Combining equations (4) and (8) with Equation (2) and solving it, we can obtain $R$ as a function of $k$ and $d$,

$$
\begin{aligned}
& R(k, d)=\frac{-3 \pi(1-k)^{2}}{24(1-k)}+ \\
& \frac{\sqrt{\left[3 \pi(1-k)^{2} d^{2}\right]^{2}-48(1-k)\left[2(1-k)^{3} d^{2}-2 d^{2}\right]}}{24(1-k)} .
\end{aligned}
$$


The electrical resistance of the increment of volume between the plane $z=z^{*}$ and $z=z^{*}+d z$ can be expressed as,

$$
d R^{*}=\frac{d z}{\sigma S^{*}}
$$

where $\sigma$ is the particle conductivity, $(m \cdot \Omega)^{-1} ; S^{*}$ is the particle cross sectional area in the $z=z^{*}$ plane, $\left(m^{2}\right)$; and $d z$ is the height of the integral unit, $(m)$.

Therefore, integrating over the same region of interest, i.e. $-h / 2<z^{*}<+h / 2$, the particle resistance, $R_{\text {particle, }}$ can be expressed as,

$$
\mathbf{R}_{\text {particle }}=2 \int_{b}^{+h / 2} \frac{d z}{\sigma S^{*}},
$$

After substituting Equation (6) into Equation (11), we get the particle resistance,

$$
\mathrm{R}_{\text {particle }}(k, d)=\frac{2}{\sigma \pi} \int_{b}^{+h / 2} \frac{d z}{\left[\sqrt{\left(\frac{h}{2}\right)^{2}-z^{2}}+R(k, d)\right]^{2}} .
$$

\section{Electrical Resistance Analysis of a Silver ACA Particle}

Equation (12) is the electrical resistance function for a metal ACA particle, assuming that the particle is not cracked or crushed and also that it does not indent into the chip bump or substrate pad. From this mathematical equation, the electrical conduction characteristics of a metal ACA can be determined from the particle size and transformation degree, i.e. $d$ and $k$. Solid metal ACA particles, made from ductile materials such as $\mathrm{Ag}$, can endure relatively large deformations [1], therefore they are treated as perfectly deformable balls in this paper. In some cases, such particles become cracked, however the direction of the crack is normally perpendicular to the packaging plane, as described in reference [11], and therefore such cracks do not affect the particle conductivity. Furthermore, if the particles are crushed, they will lose mechanical strength, may have an increased electrical contact resistance, and potentially lead to reliability problems, so the bonding process must be designed to protect the particle from excessive crushing.

Equation (12) is not solvable using algebraic methods, so a numerical solution was obtained using MathCAD. The predicted resistance of silver ACA particles is shown in Fig. $5-\mathrm{a}$ and $\mathrm{b}$, where the silver conductivity is $0.63 \times 10^{8}(\mathrm{~m} \cdot \Omega)^{-1}, d$ is varied from $3 \mu \mathrm{m}$ to $20 \mu \mathrm{m}$ and $k$ varied from 0.1 to 0.9 . Although the particle resistance is determined by both the particle size, $d$, and the transformation degree, $k, k$ is the key factor in determining the resistance. It can be seen from the figures that the larger the metal particle is and the deeper the transformation, the lower the particle resistance is.

Open circuits may result when metal coated particles are compressed by more than $33 \%(k>0.33)$ of their original size, while intermediate resistances occur at less than $20 \%$ compression [16]. The most stable values of resistance have been reported for a transformation degree of $40 \%$ for metal coated particles $[8,17]$. However, for solid particle such values of $k$ for a low and stable resistance have not been reported. Thus, in this paper it is assumed that for $k<0.6$ the particles are not crushed. On the other hand, if the transformation degree is too low, the area of contact will be
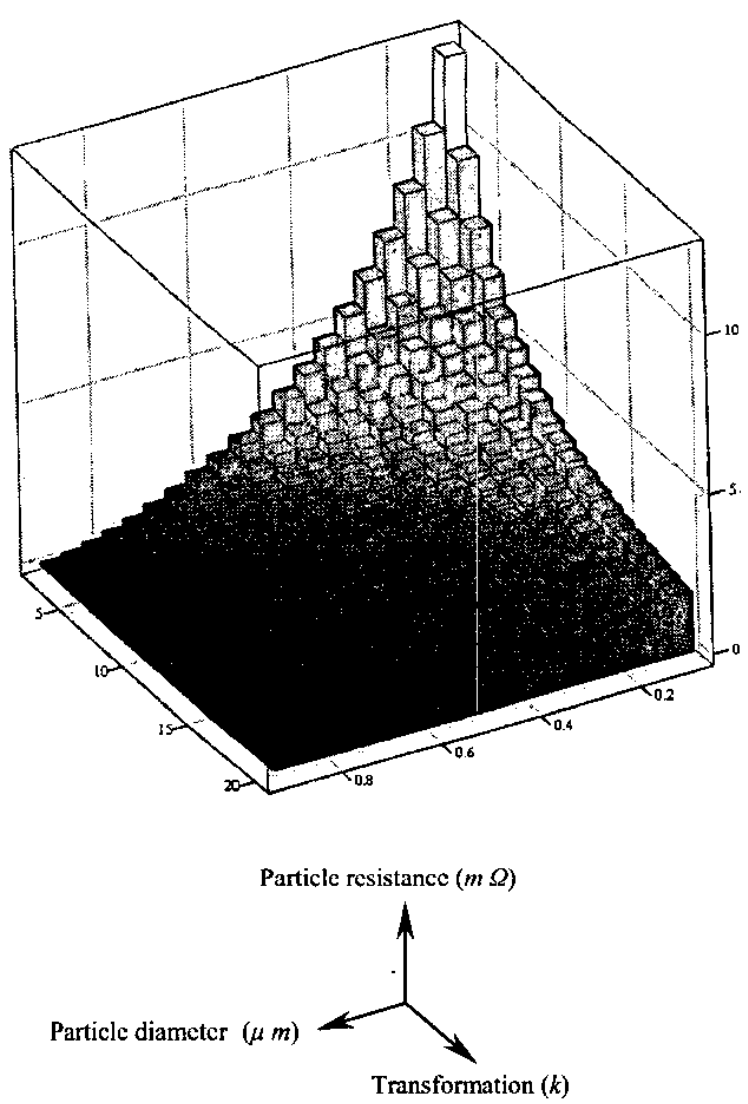

a)

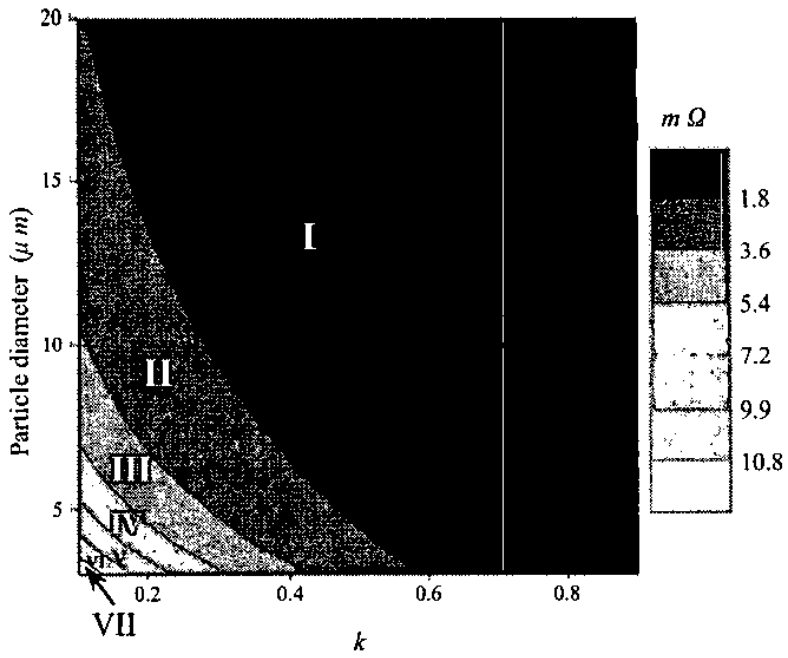

b)

Figure 5. Predicted particle resistance as a function of $k$ and $d$ 
small, resulting in a large constriction resistance at the contact area $[18,19]$, also the lower transformation degree is, the larger particle resistance will be as shown in Fig. 5. Therefore, it is assumed that a minimum value of $k$ of 0.3 is required to ensure an acceptable contact constriction resistance and a reasonable particle resistance. So the optimum transformation degree is in the range, $0.3<k<0.6$.

The particle resistance plots in Fig. 5 can be divided into three areas, a high resistance area (regions III, IV, V, VI and VII), an acceptable resistance area (region II) and a low resistance area (region I). Combinations of $d$ and $k$ within the low resistance area are not suitable to be used because they require excessively high degrees of transformation or very large particle diameters. Too large a transformation will cause the particle to be crushed and too large a particle diameter will reduce the number of trapped particles per connection and may cause reliability problems. In the high resistance areas, the particle resistances are too large to be usable in typical applications. It can be seen from Fig. 5-a that when the transformation is less than about $30 \%$, i.e. $k<0.3$, even if the particle is as large as $5 \mu \mathrm{m}$, the resistance is still in the large resistance areas, where the particle resistance is more than 3.6 $m \Omega$. If $k$ is larger than about 0.6 , then the particle resistances fall within area I, where the particle resistances are less than $1.8 \mathrm{~m} \Omega$, but normally if the transformation is more than $60 \%$, the particle will be crushed. Therefore, area II is the better area to be used, which has resistances ranging from about 1.8 $m \Omega$ to $3.6 \mathrm{~m} \Omega$. Considering the particle transformation should between $30 \%$ and $60 \%$ in the areas II, the optimum particle diameter should be from about $4 \mu \mathrm{m}$ to $9 \mu \mathrm{m}$, otherwise the particle resistances are somewhat large. This is therefore also a reason why the particle diameters for ACAs should not be less than $4 \mu \mathrm{m}$. If they are less than $4 \mu \mathrm{m}$, the particle resistances will be high even if the transformation is more than $30 \%$. It also can be seen from Fig. 5-b that when the particle diameter is increased to more than $10 \mu \mathrm{m}$, it has little affect on the particle resistance for any safe degree of transformation, however too large particles are not suitable for use in fine pitch electronics packaging.

\section{Conclusions}

This paper has presented a new method to calculate the contact area and electrical resistance of a solid metal conductor particle as a function of the particle diameter and degree of transformation.

Using this new model, the following conclusions can be reached:

The degree of particle transformation has a greater affect than the particle diameter on the particle resistance.

The larger the conductor particle is, the lower the particle resistance is however, if the resin diameter is more than 10 $\mu \mathrm{m}$, it does not significantly affect the particle resistance at any acceptable degree of transformation.

Future work will provide a comparison of the conduction behaviour of solid metal and metal coated polymer ACA conductor particles.

\section{Acknowledgements}

The authors would like to thank Professor Y. C. Chan of the Department of Electronic Engineering, City University of Hong Kong and Professor Johan Liu of the School of Mechanical and Vehicular Engineering, Chalmers University of Technology, Sweden for their advice during the completion of this work.

\section{References}

1. Liu J., Conductive Adhesive for Electronics Packaging, Electrochemical Publications Ltd, Port Erin, Isle of Man, 1999.

2. Liu J., "ACA Bonding Technology for Low Cost Electronics Packaging Applications-Current Status and Remaining Challenges," Soldering \& Surface Mount technology, 13/3, 2001, pp. 39-57.

3. Dudek, R., Meinel, S., Schubert, A., Michel, B., Dorfmuller, L., Knoll, P.M. and Baumbach, J. "Flow Characterization and Thermo-Mechanical Response of Anisotropic Conductive Films," IEEE Transactions On Components and Packaging Technology, Vol. 22, No. 2, June 1999, pp. 177-185.

4. Chan Y. C., Hung K. C., Tang C. W. and Wu C. M. L., "Degradation Mechanism of Anisotropic Conductive Adhesive Joints for Flip Chip on Flex Applications," Proceedings of the $4^{\text {th }}$ International Conference on Adhesive Joining and Coating Technology in Electronics Manufacturing, Espoo, June 2000, pp. 141-146.

5. Yin C. Y., Alam M. O., Chan Y. C., Bailey C. and Lu H., "The Effect of Reflow Process on the Contact Resistance and Reliability of Anisotropic Conductive Film Interconnection for Flip Chip on Flex Applications," Microelectronics Reliability, Vol. 43, 2003, pp. 625-633.

6. Williams D. J., Whalley D. C. and Boyle O. A., "The effects of conducting particle distribution on the behaviour of anisotropic conducting adhesives - non uniform conductivity and shorting between connections," Journal of Electronic Manufacturing, Vol. 3, June 1993, pp. 85-94.

7. Mannan S. H., Whalley D. C.; Ogunjimi A. O. and Williams D. J., "Assembly of planar array components using anisotropic conducting adhesives - a benchmark study: Part II - Theory," IEEE Transactions on Components, Packaging and Manufacturing Technology, Part C, Vol. 19, No. 4, October 1996, pp. 264-269.

8. Shiozawa N., Isaka K. and Ohta T., "Electric Properties of Connections by Anisotropic Conductive Film," Journal of Electronics Manufacturing, Vol. 5, No. 1, March, 1995, pp. 33-37.

9. Shi F. G., Abdullah M., Chungpaiboonpatanna S., Okuyama K., Davidson C. and Adams J. M., "Electrical Conduction of Anisotropic Conductive Adhesive: Effect of Size Distribution of Conducting Filler Particles," Material Science in Semiconductor Processing, 2, 1999, pp. 263-269.

10. Wu S. X, Hu K. X. and Yeh, C. P., Contact reliability modelling and material behaviour of conductive adhesives under thermomechanical loads in Liu J. (Ed.), Conductive Adhesive for Electronics Packaging, Electrochemical 
Publications Ltd, Port Erin, Isle of Man, 1999, chapter 6, pp. 120-122.

11. Dou G., Chan Y. C. and Liu J., "Electrical Conductive Characteristics of Anisotropic Conductive Adhesive Particles," Journal of Electronic Packaging, ASME, Vol. 125, December 2003, pp. 609-616.

12. Määttänen J., "Contact Resistance of Metal-coated Polymer Particles Used in Anisotropically Conductive Adhesives," Soldering \& Surface Mount technology, 15/1, 2003, pp. 12-15.

13. Fu Y., Willander M., and Liu J., "Statistics of Electric Conductance Through Anisotropically Conductive Adhesive," IEEE Transactions On Components and Packaging Technology, Vol. 24, No. 2, June 2001, pp.250-255.

14. Chiang K. N., Chang C. W. and Lin J. D., "Analysis of ACA/ACF package Using Equivalent Spring Method," Proceeding of $3^{\text {th }}$ Conference on Electronics Packaging Technology, Singapore, December, 2000, pp. 110-116.

15. Dou G., Whalley D. C. and Liu C., Proceeding of the $6^{\text {th }}$ IEEE Conference on High Density Microsystem Design and Packaging and Component Failure Analysis (HDP'04), Shanghai, China, June 2004, pp. 264-276.

16. Mannan S. H., Oguibe C. N., Whalley D. C. and Williams D. J., "Effects of gap height on conduction within anisotropic conducting adhesive assemblies," Journal of Electronic Manufacturing, Vol. 7, September 1997, pp. 211-224.

17. Lyons A. M. and Wong C. P., Recent Advances and Evaluation of Anisotropically Conductive Adhesive for Microelectronics Assembly in Liu J. (Ed.), Conductive Adhesives for Electronics Packaging, Electrochemical Publications Ltd, Port Erin, Isle of Man, 1999, chapter 8, pp. 189.

18. Kivilahti J. K. and Savolainen P., Design and Modelling of Solder-filled ACAs for Flip-chip and Flexible Circuit Applications in Liu J. (Ed.), Conductive Adhesive for Electronics Packaging, Electrochemical Publications Ltd, Port Erin, Isle of Man, 1999, chapter 7, pp. 186-187.

19. Holm R. Electric Contacts, Theory and Application, Springer-Verlag, Berlin, Heidelberg, New York, 1967. 